\title{
NOTAS SOBRE LA INMIGRACIÓN ARGENTINA EN LA PRECORDILLERA ANTOFAGASTINA DURANTE EL CICLO SALITRERO ${ }^{1}$
}

\author{
José Antonio González Pizarro²
}

\section{* Introducción}

\section{Resumen}

Se examina el corpus de documentos del Departamento de Extranjería del Registro Civil e Identificación de Antofagasta, entre los años 1900 y 1930 , relativos a la presencia de argentinos en las localidades precordilleranas del interior de la región, así como en el núcleo CalamaChuquicamata durante el auge del ciclo salitrero. La inmigración argentina se relacionó con la continuidad histórica de nexos sociales y comerciales en el área de la puna de Atacama. Los flujos de profesionales y oficios calificados se acomodaron en las actividades mineras y comerciales, mientras los no calificados en el ámbito agropecuario.

Palabras claves: Desierto de Atacama - inmigración argentina ciclo salitrero.

Here, we present the corpus of documents kept by the Immigration Department and the Office of Civil Registry and Identification in Antofagasta, between 1900 and 1930, related to the presence of Argentines both in the towns in the Andean foothills and the CalamaChuquicamata nucleus during the peak of the nitrate cycle. Argentine immigration was related to the historical continuity of social and commercial links in the Atacama area. The flow of professionals and those in specialized fields became involved in mining and commercial activities, while individuals in non-specialized jobs found work in agriculture and livestock.

Key words: Atacama desert - Argentinean immigration - Nitrate cycle. Recibido: marzo 2010. Aceptado: septiembre 2011.
Durante el apogeo del ciclo salitrero de la provincia de Antofagasta, que se extendió entre 1880 y 1930, la minería calichera gravitó en todos los ámbitos de la vida regional (Bermúdez 1984). Basta indicar que una actividad tan distante como la agrícola de la precordillera, proveyó de una significativa cantidad de fardos de forraje y de otros recursos para la mantención del ganado mular empleado para el transporte y tracción de carretas entre los mantos calicheros y las canchas de recepción de las oficinas salitreras destinadas a la molienda y elaboración del nitrato de sodio (González 2003). Otro ejemplo, fue la reglamentación que, en la década de 1910, favoreció el uso consuntivo de los recursos hídricos de la hoya del río Loa, favoreciendo las actividades mineras en desmedro de las agrarias (Tala y González 1996). Por su parte, el sector terciario de las urbes quedó supeditado a los ciclos propios de las transacciones del producto en el mercado de Londres (Cariola y Sunkel 1982).

Esta actividad primaria minera se desarrolló durante el ciclo de operación del sistema Shanks, que primó como tecnología hegemónica durante el período, perfilando la economía regional. Bajo su égida se implementaron los principales medios de conectividad de la zona de Antofagasta, permitiendo operar las redes ferroviarias privadas, tanto de carga como de pasajeros (Blakemore 1996; González 2012). Toda esta bullente faena exigió un contingente importante de mano de obra calificada y

\footnotetext{
1 Proyecto FONDECYT 1070032 “La construcción de la triple frontera peruana, boliviana y chilena, 1902-1929”; Iniciativa Científica Núcleo Milenio Proyecto "Ciencia Regional y Políticas Públicas".

2 Facultad de Humanidades, Escuela de Derecho, Universidad Católica del Norte. Avenida Angamos o610, Antofagasta, CHILE. Email:jagonzal@ucn.cl.
} 


\begin{tabular}{|l|c|c|c|c|c|c|c|c|c|}
\hline & \multicolumn{3}{|c|}{ POBLACIÓN URBANA } & \multicolumn{3}{c|}{ POBLACIÓN RURAL } & \multicolumn{3}{c|}{ POBLACIÓN TOTAL } \\
\hline Nacionalidad & Hombres & Mujeres & Totales & Hombres & Mujeres & Totales & Hombres & Mujeres & Totales \\
\hline Alemania & 970 & 32 & 1002 & 141 & 35 & 176 & 111 & 67 & 1178 \\
\hline Argentina & 400 & 191 & 591 & 1010 & 278 & 1288 & 1410 & 469 & 1879 \\
\hline Austria- Hungría & 596 & 115 & 711 & 170 & 9 & 179 & 766 & 124 & 890 \\
\hline Bolivia & 1024 & 729 & 1753 & 2531 & 1544 & 4075 & 3555 & 2273 & 5828 \\
\hline España & 741 & 114 & 855 & 308 & 35 & 343 & 1049 & 149 & 1198 \\
\hline Gran Bretaña & 1640 & 107 & 1747 & 289 & 15 & 304 & 1929 & 122 & 2051 \\
\hline Italia & 734 & 95 & 829 & 130 & 9 & 139 & 864 & 104 & 968 \\
\hline Perú & 648 & 378 & 1026 & 546 & 177 & 723 & 1194 & 555 & 1749 \\
\hline Total & 8383 & 1872 & 10255 & 5422 & 2123 & 7545 & 13805 & 3994 & 17800 \\
\hline
\end{tabular}

Tabla 1. Nacionalidad de extranjeros, sexo e inserción en la población urbana y rural.

ruda de operarios y obreros nacionales y extranjeros -especialmente durante el período anterior a 1926 - pues el trabajo se caracterizó por la aplicación de una tecnología pre-industrial o pre-mecanizada (Garcés 1999; González 2003). ${ }^{3}$ Por su parte, la incidencia del emergente mineral de Chuquicamata (a partir de la segunda mitad de la década de 1910) era todavía marginal pero ya anticipaba el polo de desarrollo que englobaría posteriormente al área de Calama y a determinados pueblos precordilleranos (Vergara 2008).

Si observamos el panorama productivo regional, podemos indicar que efectivamente fue atractivo para la migración transfronteriza tanto de Bolivia como de Argentina y, en menor medida, de Perú, dado que los dos primeros países colindaban con la entonces provincia de Antofagasta y habían mantenido relaciones pre-republicanas de contacto (Mora y Romero 1999).

Nuestra exposición dará cuenta de la presencia del contingente argentino en el área de la precordillera andina de la provincia de Antofagasta, que abarcó los principales nodos urbanos y mineros de Chuquicamata y Calama; los agropecuarios de San Pedro de Atacama, Toconao y otras localidades; y aquellos vinculados a la actividad ferroviaria, como Cebollar y otras estaciones del tendido del ferro-

3 En efecto, en 1926 comenzó la construcción de la oficina salitrera María Elena, que dio inicio a la implementación y expansión del sistema Guggenheim, tecnología de extracción y elaboración del nitrato de sodio que superó en eficiencia y calidad al sistema Shanks (González 2003) carril de Antofagasta a Bolivia, especialmente a partir del Tratado de Paz y Amistad entre Chile y Bolivia de 1904.

En tal sentido, se trata de relacionar las cualificaciones de oficios de esa inmigración, con las reales posibilidades de inserción en el mercado laboral, fuera éste agropecuario o minero. En el primer caso, habría que determinar en qué medida gravitó el intenso comercio de ganado entre las provincias del noroeste argentino y los cantones salitreros del desierto, e identificar la presencia de oficios asociados con el arrieraje, con el objeto de establecer si -junto a los tradicionales lazos de amistad o compadrazgos-, fueron condiciones necesarias y suficientes para determinar redes sociales y asentamientos definitivos en la precordillera y puna occidental. Por otra parte, respecto al mercado minero, se pretende establecer si los asentamientos argentinos en Calama y en Chuquicamata se debieron más a la cualificación laboral demandada por el mercado cuprífero y minero en general, o a la confluencia de oficios requeridos y redes sociales informantes y receptoras de dicha inmigración.

Nos interesa también visualizar si tal presencia fue una continuidad de las relaciones casi inveteradas establecidas en la zona puneña de Atacama, con sus consiguientes redes sociales; o si obedeció a una nueva realidad de contactos que motivó a contingentes argentinos de las provincias del noroeste (Jujuy, Salta, Tucumán) así como de zonas no circumpuneñas, como Catamarca, la Rioja, e incluso Buenos Aires, a tentar fortuna en poblados mineros y agropecuarios del desierto de Atacama. 


\begin{tabular}{|c|c|c|c|c|c|c|c|c|c|}
\hline \multirow[b]{2}{*}{ Nacionalidad } & \multicolumn{3}{|c|}{ POBLACIÓN SOLTEROS/VIUDOS } & \multicolumn{3}{|c|}{ POBLACIÓN CASADOS } & \multicolumn{3}{|c|}{ POBLACIÓN TOTAL } \\
\hline & Hombres & Mujeres & Totales & Hombres & Mujeres & Totales & Hombres & Mujeres & Totales \\
\hline Bolivia & 3.567 & 2.016 & 5.583 & 2.743 & 2.040 & 4.783 & 6.310 & 4.056 & 10.366 \\
\hline Argentina & 2.408 & 2.003 & $4 \cdot 411$ & 1.349 & 1.288 & 2.637 & 3.757 & 3.291 & 7.048 \\
\hline Perú & 1.871 & 1.968 & 3.839 & 1.277 & 1.107 & 2.384 & 3.148 & 3.075 & 6.223 \\
\hline
\end{tabular}

Tabla 2. Nacionalidad, estado civil y sexo de los extranjeros en la provincia de Antofagasta.

Para nuestro estudio hemos tenido acceso al corpus de documentación relativa a prontuarios llevados por el Departamento de Extranjería del Registro Civil e Identificaciones de Antofagasta, entre los años 1900 y $1930 .{ }^{4}$ Además, hemos complementado y compulsado esa información, con los repertorios eclesiásticos de las parroquias de Calama y Chuquicamata, específicamente los registros de matrimonios y bautismos efectuados entre 1881 y 1930. No obstante, como la documentación parroquial no siempre consigna la localidad argentina de origen, hemos privilegiado los prontuarios para la determinación de la procedencia geográfica y la contabilidad demográfica en los distintos períodos que hemos identificado en la historia binacional.

\section{La inmigración argentina, su procedencia geográfi- ca y su asentamiento en la provincia de Antofagasta}

La inmigración extranjera en Chile llegó a su cenit en el censo de 1907, alcanzando el 4.2\% de la población total del país (Censo de Población 1908). En la provincia de Antofagasta, ese porcentaje era superado con creces, puesto que la población extranjera ascendía al 19.5\%, destacándose el contingente boliviano con cerca de un $40 \%$. En los censos posteriores se observa una disminución gradual que, en 1920 alcanza solo un 3\% (Censo de Población 1925), reduciéndose más aún en 1930 (Censo de Población 1931). En este contexto, se puede apreciar un cambio significativo de la inmigración desde los países fronterizos a Chile entre 1907 y 1930.

El censo de 1907 (Censo de Población 1908) estableció una concentración de la población latinoamericana en las áreas rurales: del total de bolivianos ( 5.828 indivi-

4 En la actualidad esta documentación forma parte del Archivo Histórico de la Universidad Católica del Norte. duos), 4.075 se contabilizaron entre la población rural y 1.753 como población urbana. Por su parte, de un total de 1.879 argentinos, 591 fueron registrados como población urbana y 1.288 como población rural. El censo de 1907 presentaba para la provincia de Antofagasta una proporción interesante de concentración demográfica de las distintas nacionalidades latinoamericanas, que sugería una proclividad a asentarse en los espacios geográficos que les fueren más apropiados, no tanto en relación a su falta de preparación laboral o incluso a su grado de alfabetización, sino a modalidades socioculturales más pertinentes a su inserción social. Con los contingentes europeos se observa lo contrario, puesto que gracias a su formación laboral, a sus inversiones de capitales importantes en los centros urbanos y mineros, y a su procedencia de zonas urbanas de sus respectivas naciones, tendieron a establecerse en las áreas que posibilitaban no solo su manutención sino también su movilidad social en la sociedad regional. El censo de 1907 (Tabla 1) nos revela claramente lo aseverado.

De este registro se desprende que la concentración de la población europea afianzaba el proceso de urbanización, en contraposición con la migración transfronteriza que incidía, en su generalidad, en la perpetuación de la sociedad tradicional agraria -como postulara hace algunas décadas Jorge Hardoy (1972) - o bien, en la configuración de un cordón periférico urbano, alimentado por los inmigrantes más pobres, que se confundía con rasgos de marginalidad social o con la directa exclusión (Morse 1973; Lezama 2005; Gutiérrez 1983; Scobie 1984; Solimano 2008).

La inmigración argentina siempre tuvo un papel importante en las colonias extranjeras de Chile. Desde el censo de 1907 se mantuvo como el segundo contingente extranjero, después del boliviano, hasta fines de la década de 1930. El censo de 1930 (Censo de Población 1931: 167) todavía avalaba su relevancia cuantitativa (Tabla 2): 
Sin embargo, dentro del contexto latinoamericano, la migración argentina provocó la ruptura del patrón de localización rural al concentrarse mayoritariamente en las ciudades, hacia fines de la década de 1920. Hacia 1930, su distribución en las comunas de la provincia de Antofagasta refrendaba esa localización urbana, dado que en la comuna de Tocopilla había 40 argentinos; en la del Toco 67; en la de Taltal 10; en la de Aguas Blancas 2; en la de Mejillones 10 y en la de Catalina 81. Las comunas de mayores concentraciones eran Antofagasta con 110; Sierra Gorda con 118 y la más importante, Calama, con 268. Cuando se trataba de las comunas de Antofagasta o de Tocopilla, la agrupación poblacional era en torno a las ciudades respectivas.

Si observamos que Tocopilla, Taltal, Mejillones y Antofagasta corresponden a centros urbanos costeros, también se debe considerar la presencia argentina en las actividades mineras no calicheras (Sierra Gorda, Catalina), además de la pampa salitrera (Toco, Aguas Blancas), notándose la fuerte concentración en torno a la comuna de Calama, que agrupaba Chuquicamata, San Pedro de Atacama y los poblados precordilleranos y estaciones ferroviarias (Censo de Población 1931: 183-186; 197).

Es necesario mencionar que el poblado de Calama y el campamento-mineral de Chuquicamata experimentaron, a partir de 1907, un creciente desarrollo demográfico en desmedro de la significación de los poblados precordilleranos. Así, por ejemplo, Calama vio un incremento poblacional de 2.856 habitantes en 1907 a 3.175 hacia 1920, hasta situarse con 5.407 almas en 1930; mientras, Chuquicamata elevaba sus guarismos de 9.715 en 1920 a 13.346 en 1930.

Si examinamos la población argentina proveniente de la documentación del Registro de Extranjería con residencia en el área precordillerana de la actual región de Antofagasta -que mantiene las demarcaciones de la antigua provincia- constatamos una procedencia desde las provincias de Salta, Jujuy y Catamarca que coincide con las proximidades a las localidades chilenas de mayor preferencia: en orden decreciente éstas corresponden a Calama, Chuquicamata, San Pedro de Atacama, Toconao y Cebollar. Habrá que notar que del total de argentinos(as) llegados(as) a la provincia, 20\% provino desde Buenos Aires; 24\% de Catamarca; 13\% de Salta; 9\% de La Rio- ja; $8 \%$ de Mendoza; 7\% de San Juan; 4\% de Tucumán; $4 \%$ de Santa Fe, etc. Si reparamos los destinos de este flujo migratorio, los datos confirman algunas leyes de Ravenstein (1885, 1889): 62,9\% migran a la ciudad de Antofagasta; $8,02 \%$ a Calama; $7,25 \%$ a Chuquicamata; $3,44 \%$ a San Pedro de Atacama y 1,53\% a Cebollar. Según Ravenstein, quienes se desplazan a largas distancias, van preferentemente a los grandes centros del comercio o de la industria, mientras que en las migraciones de corta distancia predominan las mujeres. En ambos casos el móvil es el económico (Arango 1985), que podríamos matizar con la existencia de las redes sociales de recepción. Podemos señalar que del total de 86 argentinos radicados en la precordillera, un 77\% provenía de la Puna oriental, es decir, de la amplia franja puneña que se integró al Territorio de los Andes de la República Argentina.

Del registro de prontuarios de argentinos(as) establecidos en el área andina chilena, de un total de 1.061 individuos, encontramos que 86 casos corresponden a:

a. Personas procedentes de la provincia de Salta (25), provenientes de poblados próximos a la frontera puneña como Pastos Grandes, Los Cobres y Lucrecia, así como otros más cercanos a la estación ferroviaria de Cebollar y a los poblados coloniales de San Pedro de Atacama y de Toconao. De Cachi, La Poma, Lucrecia, Molinos, Rosario de Lerma y San José son los que se dirigen hacia Calama y Chuquicamata, que totalizan 20 .

b. Procedentes de la provincia de Jujuy (13), que indicaban poblados también cercanos a la frontera con Chile, como Rinconada, Tilcara, Ugina. Cinco de ellos se quedan en San Pedro de Atacama y Cebollar.

c. De la provincia de Catamarca arriban 29 argentinos, que mencionan como lugares de nacimiento a Tinogasta, Fiambalá, Laguna Blanca, Andalgalá, Belén, San Juan, San Fernando. De ellos, diez señalaron a Tinogasta y seis a Fiambalá, que son los lugares más cercanos a la frontera chilena. Sin embargo, solamente tres se radicaron en la precordillera: uno en Cebollar, otro en San Pedro de Atacama y el tercero en Toconao. Diez se ubicaron en Chuquicamata y el resto en Calama. 


\begin{tabular}{|l|c|c|c|}
\cline { 2 - 4 } \multicolumn{1}{c|}{} & \multicolumn{3}{c|}{ ARGENTINA } \\
\cline { 2 - 4 } \multicolumn{1}{c|}{} & \multicolumn{2}{c|}{ sexo } & Total \\
\hline PERÍODO & Hombre & Mujer & $0,00 \%$ \\
\hline ANTES DE 1842 & $0,00 \%$ & $0,00 \%$ & $0,00 \%$ \\
\hline DE 1855 A 1869 & $0,00 \%$ & $0,00 \%$ & $0,57 \%$ \\
\hline DE 1869 A 1882 & $0,68 \%$ & $0,00 \%$ & $5,34 \%$ \\
\hline DE 1882 A 1896 & $5,24 \%$ & $5,88 \%$ & $12,60 \%$ \\
\hline DE 1896 A 1909 & $12,76 \%$ & $11,76 \%$ & $23,85 \%$ \\
\hline DE 1909 A 1922 & $25,97 \%$ & $12,94 \%$ & $29,77 \%$ \\
\hline DE 1922 A 1936 & $29,61 \%$ & $30,59 \%$ & $27,86 \%$ \\
\hline DE 1936 A 1949 & $25,74 \%$ & $38,82 \%$ & $0,00 \%$ \\
\hline DE 1949 A 1953 & $0,00 \%$ & $0,00 \%$ & $100,0 \%$ \\
\hline TOTAL & $100,0 \%$ & $100,0 \%$ & \\
\hline
\end{tabular}

Tabla 3. Distribución de la población según el año de entrada.

Sorprende, además, constatar argentinos de otras provincias alejadas de la hoya altiplánica, como por ejemplo de Buenos Aires (2), de Chubut (1), de Mendoza (1), de Córdoba (1) y de la Plata (1); además de seis personas de La Rioja y tres de San Juan.

El flujo migratorio argentino en la provincia de Antofagasta permite establecer no solo los grupos etarios, sino también las diferentes cohortes cuya variabilidad se corresponde con las fechas de mayor atracción del ciclo salitrero y de la actividad minera cuprífera; así como de las actividades terciarias en centros urbanos y las de faenas de altura, vinculadas con las estaciones ferroviarias y agrícolas (Tabla 3).

Podemos indicar que después de finalizada la Guerra del Pacífico (1879-1884), se aprecia un flujo migratorio argentino más gradual y sostenido en el tiempo que comprende hasta la década de 1940 . No obstante, la estadística total de los argentinos posibilita leer tales flujos vinculados con las relaciones diplomáticas entre Chile y Argentina, así como en las relaciones paradiplomáticas a nivel de poblaciones fronterizas, entre el norte chileno y el noroeste argentino. Si analizamos las cohortes de fechas entre 1879-1899, hitos que demarcan el inicio de la Guerra del Pacífico y las negociaciones que dieron término al diferendo de la Puna de Atacama entre Chile y Argentina (que significó la cesión a esta última de pobla- dos ocupados por Chile, pero que pertenecían a Bolivia, y otros que Bolivia entregó a Argentina) encontramos a 28 argentinos que se trasladan por la Puna de Atacama (Benedetti 2005a: 155-183; González 2010).

Consideremos que la información parroquial, no coincidente con los patronímicos de los prontuarios señalados, arroja para este período 16 hombres y 3 mujeres que contraen matrimonio y/o son bautizados o bien son registrados como testigos. En el año 1883, seis argentinos participan en bautizos en Chiu Chiu (AOC, Chiu Chiu, libro V, bautismos). Entre 1881 y 1889 , dos argentinas se casan, en 1890 lo hace un argentino, en 1892 dos argentinos se suman con cuatro compatriotas como testigos de contrayentes. En 1893, figura un argentino como testigo; en 1895 un hombre y una mujer y en 1896 un argentino (AOC, Calama, libro I: Matrimonios 1884-1896).

Los años transcurridos entre 1902 y 1915 marcan un cambio en las relaciones estatales entre Chile y Argentina, pues se verifican las firmas de los denominados Pactos de Mayo de 1902 y el Pacto del ABC, donde se incorporó Brasil. Se trató de un período de gran distensión en las fronteras, que impulsó a 35 argentinos a cruzar por los consabidos senderos de la Puna de Atacama (González 2001). En este lapso, la matrícula eclesial registra un matrimonio de un argentino en Chiu Chiu, en 1909 (AOC, Chiu Chiu, libro V: Matrimonios). En Calama, 16 argentinos se ven vinculados como contrayentes o testigos en matrimonios celebrados entre 1906 y 1915 (AOC, Calama, libro 1: Matrimonios 1906).

El período que se extiende entre 1915 y 1930 estuvo marcado por el gran tráfico fronterizo del ganado argentino hacia la pampa salitrera, los grandes comicios y esfuerzos ciudadanos en ambos lados por afianzar el ferrocarril de Antofagasta a Salta (durante toda la década de 1920), hasta coincidir, en 1930, con el cierre de la frontera para el ganado argentino por los altos impuestos de importación y la crisis mundial y salitrera en particular. Solamente cruzaron y se quedaron 26 argentinos durante ese período.

La información parroquial de los años 1915-1930 arroja tres matrimonios de argentinos registrados en Chiu Chiu: dos en 1916 y uno en 1918 (AOC, Chiu Chiu, libro V: Matrimonios); cuatro matrimonios realizados en Chuquicamata, uno en 1920, otro en 1922, un tercero en 1923 y un 


\begin{tabular}{|l|c|c|c|}
\cline { 2 - 4 } \multicolumn{1}{c|}{} & \multicolumn{3}{c|}{ ARGENTINA } \\
\cline { 2 - 4 } \multicolumn{1}{c|}{} & \multicolumn{2}{c|}{ sexo } & \\
\hline GRUPOS EDAD & hombre & mujer & Total \\
\hline MENOS 10 AÑOS & $0,9 \%$ & $1,2 \%$ & $1,0 \%$ \\
\hline ENTRE 10 Y 20 AÑOS & $21,6 \%$ & $24,7 \%$ & $22,1 \%$ \\
\hline ENTRE 20 Y 30 AÑOS & $30,5 \%$ & $24,7 \%$ & $29,6 \%$ \\
\hline ENTRE 30 Y 40 AÑOS & $30,1 \%$ & $27,1 \%$ & $29,6 \%$ \\
\hline ENTRE 40 Y 50 AÑOS & $10,0 \%$ & $14,1 \%$ & $10,7 \%$ \\
\hline ENTRE 5O Y 60 AÑOS & $5,5 \%$ & $2,4 \%$ & $5,0 \%$ \\
\hline ENTRE 60 Y 70 AÑOS &, $7 \%$ & $3,5 \%$ & $1,1 \%$ \\
\hline ENTRE 70 Y 80 AÑOS &, $2 \%$ & $1,2 \%$ &, $4 \%$ \\
\hline ENTRE 80 Y 90 AÑOS &, $2 \%$ & $1,2 \%$ &, $4 \%$ \\
\hline MÁS 9O AÑOS &, $2 \%$ & &, $2 \%$ \\
\hline TOTAL & $100,0 \%$ & $100,0 \%$ & $100,0 \%$ \\
\hline
\end{tabular}

Tabla 4. Distribución de inmigrantes, de acuerdo a los grupos etarios imputados al ingresar al país.

cuarto en 1927 (AOC, Chuquicamata, libro 1: Matrimonios). En Calama se verifican trece matrimonios: nueve de hombres y cuatro de mujeres, entre los años 1916 y 1929 (AOC, Calama, libro I: Matrimonios 1906).

Si bien los expedientes eclesiásticos no son tan rigurosos en consignar noticias atingentes a este estudio, como la llegada al país o el lugar de procedencia, de modo incidental encontramos datos sobre sus oficios o su localidad de nacimiento. Por el Libro I de Expedientes Matrimoniales de la Parroquia San Juan Evangelista de Calama, 1884-1896, se mencionan dos argentinos entre 1881 y 1890 , consignados como "trabajador" y "artesano", respectivamente. En el matrimonio celebrado entre un argentino y una chilena en 1892, se menciona además a dos testigos argentinos como "comerciantes" y a otros dos como "jornaleros", todos ellos residentes en Calama. La continuación del Libro I de Expedientes Matrimoniales de la Parroquia San Juan Evangelista de Calama, 19061929, menciona entre 1906 y 1909, a cinco "obreros" argentinos.

En cuanto a lugares geográficos los registros son exiguos pero, en su mayoría, confirman el flujo migratorio más próximo a la cordillera andina: Catamarca, Cayogasta y Fiambalá (AOC, Calama, libro I: Matrimonios,
1884-1896); Humahuaca, Molinos de Salta y Buenos Aires (AOC, Chiu Chiu, libro V: Matrimonios); Vinchina, Tinogasta, Catamarca (AOC, Chuquicamata, libro I: Matrimonios). Al respecto, el Libro I de Expedientes Matrimoniales de la Parroquia San Juan Bautista de Calama, 1906-1929, es más copioso: menciona a 20 argentinos provenientes de las provincias de Salta, Catamarca y territorio de los Andes, como las localidades de Cachi o Valle de Cachi, Incachi, Molinos, Susques, San Antonio del Cobre, Granada, Fiambalá, Tinogasta, Rosario.

El último período señalado en la tabla anterior, corresponde a los años 1930 y 1949, y está signado por las prohibiciones de internación de ganado argentino, la crisis mundial -que involucra gravemente a la industria salitrera-, y la inauguración del ferrocarril de Salta a Antofagasta, en 1948. Sin embargo, para nuestro propósito, el examen estadístico se cierra en la década de 1930.

Con respecto a los grupos etarios del flujo argentino que presentan los prontuarios, nos encontramos con que en su mayoría se trata de personas jóvenes, como se aprecia en la Tabla 4.

Es necesario acotar que los territorios que desplazaban y acogían flujos migratorios, atravesaron por complejos procesos de acomodamiento y adaptación a las modificaciones geopolíticas de la época. Esto ocurrió principalmente con buena parte de la Puna de Atacama, cuya sesión a Argentina afectó a la provincia de Antofagasta en lo político-administrativo y en la jurisdicción eclesiástica. En el caso argentino, llevó a establecer en 1900 el Territorio Nacional de los Andes, que perduró hasta 1943, desmembrándose a favor de las provincias de Catamarca, Salta y Jujuy. A su vez, los procesos migratorios generaron, en ambas vertientes nacionales, la necesidad de afianzar una identidad tanto en lo sociocultural como en lo político. Se podría decir que esta etapa culminó en Antofagasta hacia 1912 con su consolidación como ciudad y, a nivel regional, en 1925 con la creación del departamento de El Loa con capital en Calama, que constituyó una importante reestructuración políticoadministrativa. El Noroeste Argentino, por su parte, se esforzaba por enfrentar el desafío de la modernización agraria que afectó al sector oriental, y por superar sus limitaciones demográficas muy disímiles ante el resto del país, puesto que su población total no alcanzaba el 10\% 
del total nacional hacia fines del siglo XIX y comienzos del XX. Al igual que la provincia de Antofagasta, la inmigración extranjera recaía fuertemente en el componente boliviano, que ascendía en 1895 al 62\% del total de las inmigraciones (Piel 1998: 299-350; Justiniano 2003; González 2002, 2010a).

En este marco general, la población indígena no fue considerada por los respectivos Estados, aun cuando constituyó un nexo invalorable en el tránsito de la migración humana en la Puna de Atacama (Sanhueza 2001; Sanhueza y Gundermann 2007). Sin embargo, estas poblaciones próximas a la cordillera de los Andes, precordillera y/o puna occidental y oriental fueron demográficamente exiguas. Para el caso argentino, hacia 1914 Susques tenía 880 habitantes; Pastos Grandes, 268; Antofagasta de la Sierra, 378 y San Antonio de los Cobres, capital del Territorio de los Andes, 961 (Delgado y Göbel 2003; García y Rolandi 2003; Benedetti 2005b: 351-374).

\section{Mercado laboral, redes sociales e integración de la inmigración argentina a la sociedad regional de la precordillera andina}

El norte chileno mantuvo una conectividad con el Noroeste Argentino desde tiempos precolombinos, como lo han demostrado la arqueología y las investigaciones etnohistóricas en ambos lados (Cabezas et al. 2006). A partir de la República y a medida que la conectividad de la zona de Antofagasta se fue extendiendo más allá de los límites nacionales, abarcando a Bolivia y Argentina, paradójicamente se asistió a un decaimiento del proceso migratorio transfronterizo, que siguió empleando los senderos acostumbrados para el traslado de las recuas de ganado (González 2008a).

Se ha indicado que la actividad económica del Noroeste Argentino buscó, en su estrategia de modernización, una complementariedad con el norte chileno, basada inicialmente en la importante exportación ganadera que a su vez se correlacionó con el arrieraje argentino hacia el territorio chileno. Hacia 1910, 31 mil cabezas de ganado vacuno fueron introducidas por el "boquete Huaytiquina" hacia Antofagasta, Calama, Chuquicamata y los cantones salitreros (Michel et al. 2000). Se estimaba que el 50\% ingresaba de contrabando, con lo cual el volumen real de cabezas de ganado vacuno ascendería a unas 46.500 .
Diez años después este flujo continuaba igualmente dinámico: en 1920 atravesaron la Puna de Atacama 30.466 cabezas de vacunos, 1.842 de caballos y 36.635 de ovejas (Michel et al. 1998).

Esta fuerte actividad mercantil y poblacional en la frontera chileno-argentina provenía desde la Colonia, que contribuyó a establecer unas "rutas seculares" en un proceso de "larga duración" en el área circumpuneña (Albeck et al. 2003). El comercio entre el Noroeste Argentino y su vinculación con los puertos del Pacífico Sur fue muy importante en la etapa precedente al ciclo salitrero. También lo fueron las transacciones operadas por el arrieraje argentino con destino a la pampa salitrera de Tarapacá, donde la precordillera andina de la actual región de Antofagasta fue no solamente un paso obligado, sino una estación de hospedaje y manutención para arrieros y animales (Conti 2001, 2003; González, S. 2002).

La inmigración transfronteriza se destacó por su baja cualificación operaria o laboral y, por consiguiente, los oficios especializados o técnicos junto a las profesiones vinculadas con el aparato productivo industrial tuvieron asegurada su inserción laboral y contaron con redes sociales amplias.

La situación laboral de los migrantes transfronterizos ya era patente desde fines del siglo XIX. En efecto, la población activa extranjera que señalaba el censo de 1895 como ocupada en las ciudades, no demostraba una cualificación laboral, dada la presencia de oficios como lavanderos, gañanes, agricultores, cocineros, arrieros, distinguiéndose los hilanderos y los sastres por su grado de especialización. Estos últimos eran una fortaleza laboral boliviana (González 1993: 186 nota 76).

Si nos acercamos a la dimensión del capital social del inmigrante argentino, notamos que del total de 86 prontuarios (que corresponden a los que se ubicaron en la precordillera), 31 eran agricultores, de los cuales cuatro trabajaban en San Pedro de Atacama, tres en Toconao y la restante mayoría en las vegas de Calama. Otros 10 eran jornaleros, dos arrieros, uno trabajaba en la estación de Cebollar desde 1919, y otro en Toconao desde 1900.5

5 Archivo Histórico Universidad Católica del Norte: Archivo de Extranjería del Registro Civil e Identificaciónde Antofagasta, 
Comerciantes eran cinco, cuatro establecidos en Calama y uno en Chuquicamata. El único operador de molinos pasó desde Calama hacia la Oficina Pedro de Valdivia. El único carretero estaba en Calama, e igualmente los únicos corralero, palanquero, herrador y maquinista fijaron su residencia en la capital del Departamento El Loa. De los tres que se declararon mineros, dos se quedaron en Calama y otro se trasladó a Chuquicamata. Como chofer, un oficio más elaborado, se encontraba uno laborando en Cebollar desde 1919 (P. 19620). Mecánicos eran seis, distribuidos uno en Calama y cinco en Chuquicamata. Fogoneros eran dos, uno en Calama y otro en Chuquicamata. Dos mujeres declaraban ocuparse en labores de casa y una tercera declaraba ser cocinera.

Un peldaño más arriba en la división social del trabajo encontramos a un empleado que laboraba en Chuquicamata, a otro que era contratista en el mineral, hasta llegar a

\footnotetext{
Argentina Prontuario N ${ }^{\circ} 20007$ y Prontuario N ${ }^{\circ} 19874$. La documentación de inmigrantes argentinos se encuentra en las Cajas $n^{\circ}{ }_{1}$ (desde las letras ABE-ASE); $n^{\circ} 2$ (desde las letras AST-CAR), $\mathrm{n}^{\circ} 3$ (letras CAR-GON), n 4 (letras GOÑ-MOR), n 5 (letras MOR-RAM), n 6 (letras RAM-TAY) y n 7 (TAY-ZEP), cuya seriación de prontuarios no se corresponde con la establecida on line en el archivo de los inmigrantes argentinos del portal de la Universidad. Además, nos ha señalado la encargada del archivo que los depósitos en cajas van a desaparecer en el futuro inmediato, por motivos de conservación de este patrimonio. De este modo, nos inclinamos por hacer referencia al número de prontuario. El Prontuario (llevado a cabo por la Policía de Antofagasta, Sección de Identificación) estaba conformado por ocho páginas. La primera estaba destinada al registro de tres fotografías (que comúnmente no se anexaba); la página 2 a la Filiación (Hijo de, Nación, Provincia, Departamento, Pueblo, Nacimiento, Estado Civil, Profesión, Nivel de Alfabetización, Llegada al país, Servicio Militar, Costumbres y Hábitos [que por lo general quedaba en blanco], Individual dactiloscópica, serie y sección); la página 3 a las Señas Particulares, Parientes (Nombre, Vínculo, Domicilio, Calle Número, Prontuario Número y Sección); las páginas 4 y 5 a las Observaciones: Características Cromáticas (Talla, Color del Iris, Aréola, Periferia; Barba, Cabello, Color de la Cara; la página 6 a las Características descriptivas analizadas de perfil; contorno general (Frente, Nariz, Oreja derecha, Labios, Mentón), Características descriptivas analizadas de frente; contorno general (Implantaciones: Cabellos, Barba, Bigotes, Pera, Patilla, Párpados, Boca, Corpulencia, Cejas, Arrugas, Voz); la página 7 registraba las huellas dactilares tanto de la mano derecha como de la izquierda y la página 8 se destinaba a Observaciones. Las referencias a los antecedentes personales se citarán como $\mathrm{P}$ (Prontuario) y el número correspondiente.
}

la escala superior con la profesión ingenieril, uno en Chuquicamata como ingeniero mecánico y otro en Cebollar.

El panorama laboral discriminaba áreas geográficas, donde por ejemplo el Ferrocarril de Antofagasta a Bolivia (FCAB) tenía la necesidad de contar con un ingeniero para la mantención de sus trenes y vagones antes de penetrar la frontera boliviana. Lo mismo acontecía con la demanda de ingenieros en el mineral de cobre de Chuquicamata. Por su parte, Calama exhibía una combinación de faenas agrícolas y pecuarias, donde las vegas requerían de mano de obra y el paso del arrieraje exigía una cierta cantidad de oficios vinculados con los corrales, la manutención del ganado y el uso de carretas. Constituida en una importante estación de embarque de pasajeros, Calama albergó a palanqueros, maquinistas, fogoneros y mecánicos, combinando las actividades tradicionales de la tierra con la modernización requerida por la presencia de locomotoras de vapor y diesel.

Si nos formulamos la pregunta sobre los mecanismos que permitieron esta movilidad humana entre ambas fronteras, necesariamente debemos acudir a la teoría de las redes sociales que nos permite entender la conformación de diversos lazos, sean éstos conducentes a la institución del compadrazgo, a las vinculaciones familiares consanguíneas o a las meras relaciones de carácter laboral. Hemos tenido presente las reflexiones clásicas sobre el tópico, como de igual modo estudios puntuales relativos a sus aplicaciones y a dar cuenta del funcionamiento de las redes sociales en la realidad latinoamericana (Nadel 1966; De la Rúa 2004; Pizarro 2004; Breiger 1999).

Si la red social ha sido definida, entre otras formulaciones teóricas, como un conjunto bien definido de actores -individuos, grupos, organizaciones, comunidades, etc.que están vinculados unos a otros a través de una serie de relaciones sociales, es importante subrayar dos aspectos dinámicos en su empleo: la caracterización de estas relaciones con vista a los objetivos de la investigación y la modalidad diversa de las relaciones que pueden ser formales, institucionales, regladas o informales, permanentes o pasajeras. Los flujos migratorios se mueven en base a la estructuración de redes sociales ya sea de origen como de recepción, abarcando a veces una complejidad mayor en las relaciones extensivas al campo laboral. Las relaciones entre los actores de una red pueden darse al interior 
de una familia extensa o de las vinculaciones de compadrazgos, como también fuera de éstas donde amistades de oriundez establecen el soporte del contacto y de la decisión de emigrar, al contar con referencias de posibilidades laborales del entorno de recepción y del ambiente en general (González J. A. 2008b; 2010a, 2010b).

En la teoría de las redes sociales, la estructura relacional es la que define una situación. En este planteamiento teórico, las relaciones situacionales determinan las conductas humanas manifestadas en sus sentimientos, pensamientos y acciones, que se verifican entre los actores de la red. Es también lo que en la sociología de Pierre Bourdieu conocemos como habitus. Los habitus constituyen "principios generadores y organizadores de prácticas" (Bourdieu 1991: 928). Esta percepción del entorno se lleva a cabo en espacios sociales donde se objetivan las luchas entre los actores sociales en los distintos niveles que los involucran. Esto es el campo para el sociólogo francés. En este ámbito habría que acotar que la individuación de las percepciones, como parte de un sistema de "signos distintivos" existente en la sociedad, está dotada de sentido alcanzando a sus prácticas sociales. El universo inmigratorio argentino contiene diversos anclajes que refieren a sus estructuras sociales originales, donde se observa sus habitus de clase, pero también de trayectorias sociales individuales, que reflejan sus habitus individuales. La inserción en la sociedad local y principalmente en el mercado laboral, consigna la dinámica social que eventualmente traerá un cambio de posición social; como escribe Bourdieu, "las condiciones en las que se ha producido el habitus no coinciden con las condiciones en las que funciona" (Bourdieu 1991a: 169-174). Esto nos conduce a visualizar los escenarios sociales en los cuales se acomoda la inmigración argentina, atendiendo a ese nexo entre la adscripción de clase y el estatus de sus profesiones u oficios. Es la diferencia que otorga identidad social a cada uno de los componentes del segmento argentino estudiado, que puede asumir no solo la diferenciación clasista, sino también étnica e incluso de género. Además de la inserción social en cuanto a condicionante de las prácticas colectivas y su asunción individual, hay que agregar que la identidad subjetiva, está ligada a la noción de ipseidad de Paul Ricoeur (ver Corcuff 2005: 117). La noción de Ricoeur, se refiere a cómo el individuo plantea su propia generación de prácticas sin desligarse completamente de su estructura social. Así tenemos las identidades sociales conjuntamente con las identidades subjetivas que agrupan -y señalan diferencias en sus historias personales- a los ingenieros y técnicos vinculados a la minería de Chuquicamata o al FCAB, y aquellas entre los comerciantes establecidos en Calama o los jornaleros dispersos en los pueblos precordilleranos. Los habitus resultantes constituyen la acomodación o recreación de las prácticas establecidas, por ejemplo, en la normativa que legitima la división social del trabajo y en el estatus que determina ritos y prácticas en el campamento cuprífero, en contraposición de los usos y costumbres consuetudinarias en el mundo rural y agrícola. Del cotejo de los datos acopiados, se puede inferir que el habitus individual logra ser más importante en las situaciones que registran un itinerario subjetivo polarizado, como puede ser el ingeniero que proviene de fuera del territorio puneño o la madre soltera que debe bautizar a su hijo ilegítimo. Un ejemplo de esto fue el bautizo en Calama el 5 de diciembre de 1883 de María de los Santos, hija natural de la argentina Candelaria Reyes, donde fueron padrinos Matías González y Carmen Alfonso (AOC, Chiu Chiu, libro V: Bautismos). Aquí puede notarse que en las "elecciones" esbozadas por Bourdieu en las que el habitus es "necesidad hecha virtud", convergen la eficacia del habitus transmitido por el sacerdote local que imparte los sacramentos, y las relaciones justipreciadas como ilícitas (bautizos de hijos naturales y matrimonio de madres solteras) con la aceptación de dicha práctica por el inmigrante. El mundo social rural o popular urbano asume la existencia de relaciones sociales laxas en el terreno moral que genera el habitus de la liturgia del apadrinamiento y del compadrazgo, respectivamente. Estos habitus sostienen las expresiones simbólicas surgidas de estas instituciones que dentro de la red social establecen una cercanía intersubjetiva que vincula el presente y futuro social: los testigos de un matrimonio o los padrinos de un bautizo.

Puede también apreciarse en el análisis de redes la concurrencia de subgrupos o clique que posibilita dos situaciones: la composición de varios puntos o actores sociales en torno a alguna categoría, sexo, edad, etc., o bien el acoger al clique como un grupo de puntos o individuos conectados mutuamente o que representan una alta densidad en las relaciones. En estas puntualizaciones cabe agregar la conceptualización de círculos sociales que constituyen superposiciones de subgrupos y que exhiben cadenas de contactos indirectos que unen a sus distintos miembros. 
Una aproximación a los prontuarios seleccionados nos arroja una realidad sobre la inmigración argentina que requiere distinguir entre relaciones no familiares, para identificar a las personas que constituyen referencias inmediatas para el individuo migrante, y relaciones con familiares que declaran a la policía de modo complementario. En las primeras puede constatarse cierta "tipología" de las relaciones que apuntan a una tríada de rasgos: nacionalidad, amistad y ámbito laboral.

Esta diferenciación de relaciones abre un abanico de posibilidades interpretativas, no solo en relación a los lugares de confluencia de los individuos, sino también al mercado laboral tocante a las actividades del área y a una eventual vinculación que estaría próxima, según fuere el caso, a lo que se ha denominado clausura social (Bassarsky 2007: 162).

Si desplegamos las distintas redes sociales concernientes a los datos que estamos empleando, tendríamos una distinción entre la red social que incentiva el viaje - las relaciones declaradas- y variados clique o subgrupos, que se desprenden de otras declaraciones que constituyen el resguardo socio-afectivo del migrante. Nos referimos a los familiares ya avecindados en la zona, aunque no necesariamente en el mismo lugar, como también a subgrupos ligados de modo indirecto por vinculaciones políticas de parentesco, que darían lugar a círculos sociales.

Hay casos de argentinos altamente calificados, como el de Luis Federico Quade Garat, nacido en Buenos Aires en 1890 y que ingresó a Chile en 1922 con título de ingeniero, que declaró no tener familiares y cuya única referencia era el ciudadano británico Lycett E.W., residente en Cebollar (P. 31870). El también ingeniero mecánico, Tomás Matew (sic) Hughes Lauder, nacido en Córdoba en 1878 y llegado a Chile en 1908, declaraba que había formado hogar con Rosa Sánchez Cáceres, con quien tuvo tres hijos, todos residentes en Oruro, Bolivia. Sus amistades en Chuquicamata era C. Penman, C. Wall y Humberto Camiroaga, viviendo en el Hotel Minery del mineral (P. 3931). El constructor Simón Reales Reales, nacido en Fiambalá en 1879, llegó a Chile con 30 años, contando con la información de su hermano que vivía en la Oficina salitrera María, señalando dos amistades en Calama, donde se asentó (P. 45454). Es posible indicar que la cualificación profesional planteó una inserción más rápida en el mercado laboral, y paradójicamente una inserción social más restringida, derivada de sus vinculaciones con pares o de similar estatus social.

Las situaciones de argentinos traídos a Chile siendo niños no fueron aisladas. Ese es el caso de Bernardino Garrido Salinas, nacido en 1878 en Puerto, pueblo de la provincia de Catamarca, que llegó a Chile en 1888. Se formó en el oficio de fogonero y no logró establecer lazos familiares -se casó con Adelia Morales pero no tuvo hijos y tampoco declaró parientes- y se relacionó con Alberto Galleguillos y Pedro Tito, a quienes mencionó como amigos de Calama, donde fijó su residencia en el momento de su empadronamiento (P. 19354). Otros fueron trasladados a más temprana edad, como Ubelindo Reales Reales, nacido en Fiambalá en 1882 y que arribó en 1884, traído por su madre -no menciona al padre- donde obtuvo experiencia como minero. Se casó con Clara Romero y el hijo de ambos residió en Calama. No declaró parientes, sino solamente referencias de dos amigos de Chuquicamata, donde se desenvolvió (P. 13997). Una situación similar, acontece con Zacarías Funes Rementería, que nacido en Fiambalá en 1890 es traído por sus padres en 1892 . Se capacita en el oficio de mecánico y se casa con Carmen L. Guerrero con quien tuvo dos hijos, con los cuales fijó su residencia en Chuquicamata, ampliando su red social con la mención de dos amigos, ambos del mineral (P. 19043). El maquinista José Guzmán Reices, nacido en Salta en 1892 fue traído por sus padres en 1897. Hacia 1921 declaraba no tener parientes y permanecer soltero, teniendo como referencias dos amigos del mineral de Chuquicamata, donde laboraba (P. 19116). Jacinto Poblete Poblete que se desempeñaba como palanquero en Calama, fue traído a los cinco años, desde el pueblo de Vinchina, en la provincia de La Rioja, donde nació en 1890 . Su vida transcurrió en Calama y formó hogar con Inocencia Cruz y su hija Eufemia y contó con la amistad de Matías Valladares y Heriberto Toro (P. 12266).

La evidencia también muestra que los casados abrieron el arco de las redes a matrimonios bajo el expediente del apadrinamiento de sus hijos, mientras los solteros tenían una red más estrecha. Incluso, en determinados casos, hacían caso omiso a ciertos prejuicios sociales. Cuando Pedro Manuel Correa, un argentino avecindado en Calama, hijo natural de Micaela Correa también radicada 
en esa ciudad, se casa con Corina de los Dolores Leito, chilena, hija legítima de Matías Leito y de L. Cruz Correa, los testigos fueron dos comerciantes, Manuela Correa del Barrio, argentina, casada, residente en Calama, y Ángel Santoro, vecino de Calama, lo cual le significó ampliar su red de relaciones en un ambiente donde ser comerciante otorgaba cierto estatus local (AOC, Calama, libro I: Matrimonios 1884-1896).

Los mecánicos lograron ampliar su red social más allá de su lugar de residencia. Julián Cruz Hevia, nacido en el pueblo de Canpejillos de la provincia de Jujuy en 1880, llegó a Chile en 1897, casándose con Rosa Tapia, tuvieron cuatro hijos y se avecindaron en la oficina salitrera Cecilia, luego de trabajar en Chuquicamata y entablar amistad con Calixto Ochoa y Camilo Pinto (P. 4036). Calixto Ochoa Paredes, nacido en Tinogasta de la provincia de Catamarca en 1885, llegó a los 19 años a Chile como mecánico, teniendo como referencia a su hermano de la Oficina Salitrera Araucana y estableciéndose en Chuquicamata donde refiere a dos amistades del mineral (P. 4753). Teófilo Vargas Fernández procedente de la provincia de Córdoba, donde nació en 1887, llegó a Chile en 1915 como mecánico, y hacia 1919 todavía permanecía soltero, siendo su única red sus dos amigos de Chuquicamata, donde se estableció (P. 4122). El también mecánico Francisco Fermeida Flores, del pueblo Rosario de Lerma, llegó a los 14 años a Chile, en 1904, estableció una familia con Petrona Aramayo con quien tuvo un hijo trasladándose a Chuquicamata donde se relacionó con Ventura Muñoz y Ceferino Quiroz, ambos del mineral (P. 19111). Menos sociable se mostró Andrés Funes Soza, nacido en Catamarca en 1886. Como mecánico, logró relacionarse con Manuel Sainz y Celestino Veas, cuando fijó su residencia en Calama (P. 19228).

Si el grupo de los mecánicos no logró en su mayoría establecer clique, los comerciantes tampoco lograron ampliar su red social, a pesar de las ocasiones que les permitía el ejercicio de aquella actividad. Así lo demuestran las situaciones de Alberto Durand Salettes, nacido en Andalgalá, Catamarca, en 1878, llegado en 1908 y casado posteriormente con María Guarch, con quien tuvo siete hijos. Su familia se radicó en Salta y él permaneció en Calama, donde entabló relaciones de amistad con Ismael Núñez y Leonidas Arenas (P. 17855). Igual realidad observamos en Isauro Saturnino Carrizo Carrizo, de Tinogasta, que llegó al país a la edad de 40 años, soltero, y señaló como referencias a los hermanos Celindo y Ramón Romero de Calama, donde se radicó (P. 18955). Similar situación es la de Juan Cataffo Ruggero, de la provincia de La Plata, que llegó en 1919 a los 25 años, y permaneció soltero, siendo sus relaciones Cirilo Escudero y Ramón Alejos, ambos de Calama (P. 7736). Distinto fue el caso de Luis Cerezo Robledo, procedente del pueblo Puesto, de la provincia de Catamarca, que llegó en plena revolución de 1891 con 22 años, se casó con Zenolén Riveros y fue padre de dos hijos, quedándose en Calama donde, además, dio como referencias a dos vecinos de aquella ciudad (P. 14994). La argentina María Barrios Barrios, de Mendoza, hija natural, llegó a los 17 años a Chile, en 1919, se desenvolvió como cocinera, y vivió con su hermana Dionisia en Calama, antes de trasladarse hacia Antofagasta, donde sus relaciones fueron Elisa Aguirre, cocinera, y María Campos, lavandera, ambas de la capital de la provincia (P. 499). Alfredo Álvarez Gandarias, nacido en Cachi, en 1848, llegó al iniciarse la Guerra del Pacífico y se desenvolvió como empleado en la ciudad de Calama, donde residían sus cuatro hermanos, pudiendo listar como relaciones a Toribio Carrazana y Juan L. Rojas, de Calama (P. 19730).

El operador de molinos Lorenzo Córdova González logró concretar una red social familiar, amplia, cuando arribó a los 20 años desde Tinogasta en 1899, casándose con Sara Lemus, con quien tuvo seis hijos, quienes se establecieron en la Oficina Pedro de Valdivia ensanchando aún más la red social, sin contar las relaciones de amistad que generó en Calama con Claudio Cruz y Luis Alberto Videla, con Feliciano Saavedra Robledo, tornero, y Pablo Guerrero Guerrero, muestrero, ambos de la Oficina Pedro de Valdivia. Córdova González transitó desde Calama hacia la Oficina salitrera Chacabuco hasta finalmente quedarse en la Oficina Pedro de Valdivia (P. 19805).

El empleado de Chuquicamata Manuel Salazar Acosta había venido desde Fiambalá en 1900, a la edad de 33 años, se casó con Ester Bustillos Mantilla, con la que tuvo seis hijos, todos residentes en Chuquicamata y se relacionó con Delfín Vargas y Julio Donoso, también del mineral (P. 4091). Una situación distinta exhibía el prontuario de Nemesio Jacinto Castillo Márquez, nacido en la provincia de San Juan en 1881, que vino a Chile en 1917 y se desempeñó como minero. Aun cuando era 
soltero, sus hermanos - siete en total, cinco mujeres y dos varones- se dirigieron hacia Antofagasta, mientras él se quedó en Calama donde se vinculó con Emeterio Quintero y Arístides López, residentes de esta ciudad (P. 19231). Timoteo Carrizo Carrizo, nacido en Antinogasta en 1879, minero de oficio, al parecer cuando enviudó decidió pasar la frontera en 1902, dejando atrás sus hijos, radicándose en Chuquicamata donde mantuvo amistad con Enrique Peralta y Benito Rojas (P. 3898). El contratista Segundo Magno Chocovare, procedente de San José de la provincia de Salta, donde nació en 1884, se casó en Chile adonde arribó en 1898, y se radicó en Chuquicamata con sus cuatro hijos, lo que abrió sus posibilidades de formar subgrupos sociales, además del sostenido con sus amigos Zenón Leiva y Octaviano Díaz, vecinos del mineral (P. 4049).

Los oficios vinculados con la actividad ganadera, como los arrieros, pudieron contar con redes sociales familiares y no familiares, como fue la situación de Juan Caro Gutiérrez, nacido en Fiambalá en 1894, quien se trasladó hacia Cebollar en 1919 movido por la presencia de sus hermanos Santos y Felisa, residentes en aquella localidad, y creando otra red de amistad con Juan Olmos y Juan Armuayo, habitantes de esa estación ferroviaria (P. 20007). El arriero José Ángel Fabián, nacido en Pasto Grande en 1895, fue traído a Chile en 1900, luego de que la localidad dejara de ser chilena (en 1899), y, al parecer, solamente estableció amistad en Toconao con Andrés Morales y Rafael Ramos (P. 19874). El caso de Manuel Carose Ramayo, de Tilcara, es distinto. De oficio chofer llegó a los 15 años, en 1919, a Cebollar sin conocer a nadie, logrando hacer amistad con Pablo Gutiérrez y Francisco Escalante, vecinos del lugar. Al igual que Caro Gutiérrez, era soltero.

Los jornaleros pudieron establecer una red social más amplia como lo testimonian determinados prontuarios. Pablo Gutiérrez Tolay, nacido en 1872 en Ugina, provincia de Jujuy, que se trasladó a Salta y desde allí cruzó la frontera vía San Pedro de Atacama en 1896. Casado con Clara Galleguillos Lavesta, tuvo cinco hijos. Establecido en Cebollar amplió su círculo social con la amistad de Vicente Bautista y Francisco Salvatierra (P. 19619). Lo mismo aconteció con Juan de Dios Oliva Armeño, procedente de La Rioja, llegó a Chile con 20 años en 1901 vía La Quiaca, se casó con Josefa Miranda y tuvo un hijo. Trabajó en Cebollar, contando con la amistad de los también jornaleros Francisco Quintanilla Roca y Emilio Valdebenito Ponce (P. 4118). Algunos jornaleros lograron sentar una red social en distintos pueblos, pero cercanos, como lo hicieron Cesilio Calva Calva, nacido en Lucrecia, provincia de Salta en 1893. Llegó niño a Chile en 1899 y se dedicó a la agricultura. Su hermana Rafaela vivía en Calama, sus amistades Luciano Palma y Carmelo Plaza eran de Calama, pero él vivía en San Pedro de Atacama (P. 19842). Similar situación fue la de Pedro Cornelio Caso Caso, de Tinogasta, agricultor que llegó a los 20 años en 1915. Casado con Juana Muñoz tuvo un hijo, fijó su residencia en San Pedro de Atacama, empero él se quedó en Calama, de donde eran también sus dos referencias Belisario Chávez y Venancio Tejerina (P. 19445). Igualmente, el caso de Clemente Gutiérrez Quispe, agricultor procedente del pueblo San Carlos de la provincia de Salta, que llegó a los 19 años en 1904, y mantuvo dos círculos sociales, uno en Calama donde residían sus cuatro hermanos y su amigo Eugenio Abarca; y el otro en San Pedro de Atacama, donde él laboraba y señalaba su otra referencia, Zenín Fúnez (P. 18459). Distinta fue la realidad de Pablo Gutiérrez Tolay, nacido en Ugina, provincia de Jujuy en 1872, que ingresó a Chile vía San Pedro de Atacama en 1896. Casado con Clara Galleguillos Lavesta fue padre de cinco hijos, todos residentes en Cebollar, y tenía como sus amistades a Vicente Bautista y Francisco Salvatierra (P. 19619).

Puede indicarse que los argentinos avecindados en pueblos menores como Toconao o San Pedro de Atacama y sin cualificación laboral, como agricultor o jornalero, tendieron a tener una red social muy local tanto en lo familiar como en lo social, como lo muestran los casos de Juan Colque Colque, procedente de la Rinconada, agricultor que se avecindó en San Pedro de Atacama (P. 19935), Félix Gutiérrez Prieto, agricultor también de San Pedro de Atacama (P. 19308), Ismael Colque Colque, procedente de Los Cobres, agricultor domiciliado en Toconao (P. 19894), Fermín Casimiro Casimiro, procedente de Laguna Blanca, agricultor en Toconao (P. 19899), Juan Bautista Barrios Mamani, de San Antonio, provincia de Salta, agricultor en Toconao (P. 19905).

Las matrículas de los antecedentes de los inmigrantes argentinos no discriminan por procedencia geográfica para fijar un patrón de asentamiento, aunque puede 
observarse que los más próximos a la frontera puneña pudieron desposarse y establecer una familia nuclear antes de los 30 años. Tal covarianza entre familia y grupo etario permite conjeturar para el área en estudio que en poblados mayores, principalmente Calama, se encuentra una tasa de célibes significativa que hace que la red social se establezca con parientes o amigos, como se aprecia en varios prontuarios, como el de Dionisio Galleguillos Galleguillos (P. 19447), Gregorio Farfán Figueroa (P. 19419), Candelario Fabián Burgos (P. 19409), Celestino Fabián Burgos (P. 19413), Valentín Cuevas Reyes (P. 19247), Inocencio Carrizo Rivera (P. 18727), Rufino Colque Chaparro (P. 19392) y Cesilio Calva Calva (P. 19842), entre otros.

\section{A modo de conclusión}

La inmigración argentina hacia la provincia de Antofagasta coincidió con otros flujos migratorios de países vecinos, principalmente Bolivia, y también con los procedentes desde Europa. Su tasa de participación en el porcentaje inmigratorio latinoamericano fue relevante pues se constituyó en la segunda colonia en el norte chileno.

Las razones de esta movilidad social transfronteriza hay que buscarlas en la situación de las provincias del Noroeste Argentino, como pudieron ser entre otras razones, la proximidad histórica de la convivencia social y del tráfico comercial en el territorio de la Puna de Atacama o el proceso de modernización que afectó a las áreas agrícolas próximas a la frontera chilena. Sin embargo, el polo de atracción laboral que ofrecía la industria salitrera y una serie de otras actividades que no requerían de mayor cualificación técnica constituyó un fuerte estímulo a la migración.

La existencia de varias vías en la cordillera de los Andes tanto para el tráfico de personas como de ganado, además de la libertad de tránsito establecida por las autoridades policiales chilenas, ${ }^{6}$ fomentó este libre paso de personas. De hecho, los prontuarios compulsados son consecuencia directa de la aplicación del convenio entre

\footnotetext{
6 Recién hacia 1910 se sugiere exhibir alguna documentación (ver, Manual Baedeker 1910: 35).
}

Policías suscrito en Buenos Aires, 7 lo que facilitó momentos de mayor fluidez de la migración argentina, como el período de 1902 a 1915 de gran acercamiento diplomático luego de las tensiones anteriores a 1899 en la frontera de la Puna de Atacama.

Puede afirmarse que los profesionales argentinos vinculados a la tecnología ferroviaria o industrial minera no requirieron de una red social para decidir su viaje, a diferencia de los oficios no calificados, jornaleros y agricultores que, paradójicamente, debieron contar con una red social doméstica y una red social de recepción (la más importante), que ayudó grandemente a la integración en la sociedad regional. La larga tradición del tráfico mercantil en el área de la puna en general, ayudó, sin duda, en la circulación de la información respecto a lo que ocurría en la precordillera chilena, como oferta laboral interesante en el ámbito de los oficios mineros y aquellos vinculados al ferrocarril y al crecimiento urbano de la ciudad de Calama. De igual modo, la costumbre de viejos oficios atingentes a lo agropecuario en poblados de la precordillera se mantuvo como una oferta de mercado significativa en el tiempo del ciclo salitrero, dada la vinculación del forraje con la industria calichera.

La crisis salitrera afectó a la oferta de mercado agropecuario precordillerano puesto que el modelo Shanks operó con carretas y mulas en el traslado desde los mantos nitrosos hasta las canchas de procesamiento. Puede acotarse que lo que Alfred Schutz (1974: 95-107) denominaría "la pauta cultural de la vida del grupo" incidió en el establecimiento y adaptación de agricultores y jornaleros en los poblados precordilleranos, pudiendo los inmigrantes no solo insertarse en el mercado laboral sino hacer una vida social y familiar. La tradición de la movilidad en el área puneña posibilitó significativamente que el mayor porcentaje de inmigrantes proviniera desde una zona común en el pasado inmediato.

\footnotetext{
7 Se trata del convenio entre las policías de Argentina, Brasil, Chile y Uruguay, de 20 de octubre de 1910, cuyo artículo 10 rezaba: "Los contratantes procurarán facilitar que toda persona honesta registre en la Oficina de Identificación, sus antecedentes y su "individual dactiloscópica" que no sólo evite injustos vejámenes, sino que sea elemento de información personal, útil en cualquier circunstancia". El texto figura en la portada de los prontuarios examinados.
} 


\section{* Referencias citadas}

\section{Abreviaturas}

AOC Archivo del Obispado de Calama

AHUCN Archivo Histórico de la Universidad Católica del Norte

\section{Fuentes inéditas}

AOC, Parroquia de San Francisco de ChiuChiu. Bautismos, Libro V, comienza en el mes de abril de 1866.

AOC, Parroquia de San Francisco de ChiuChiu. Matrimonios, Libro $\mathrm{V}$, años 1907-1933.

AOC, Parroquia de San Juan Bautista de Calama. Expedientes Matrimoniales, Libro I, Años 1884-1896.

AOC, Parroquia de San Juan Bautista de Calama Libro I de Matrimonios. Principia el ocho de junio de 1906.

AOC, Parroquia del Salvador Chuquicamata. Libro I de Matrimonios. Año 1917.

AHUCN, Archivo de Extranjería del registro Civil e Identificaciones. Argentina, cajas 1-7.

\section{Bibliografía}

ALBECK, M. E., V. CONTI y M. RUIZ, 2003. Entre les oasis d'Atacama et la Puna de Jujuy: voies de communication et mobilitédans la longuedurée. Histoire des Alpes - Storia delle Alpi - Geschichte der Alpen-Andes - Himalaya -Alpes 8: 79-98.

ARANGO, J. 1985. Las leyes de las migraciones de E.G. Ravenstein, cien años después. Revista Española de Investigaciones Sociológicas 32: 7-26.

BARROS, A. 2008. Identidades y propiedades. Transiciones territoriales en el siglo XIX atacameño. Estudios Atacameños 35: 119139.

BASSARSKY, L. 2007. Enfoque de redes sociales en las migraciones de América Latina hacia Francia. Anuario de Estudios Americanos 64 (1): 141-172.

BENEDETTI, A. 2005a. La Puna de Atacama como construcción geopolítica (1879-1900).La redefinición del mapa político argentino tras la guerra del Pacífico. Si Somos Americanos. Revista de Estudios Transfronterizos 7(2): 155-183.

2005b. Un territorio andino para un país pampeano. Geografía histórica del territorio de los Andes (1900-1943). Tesis de doctorado, Facultad de Filosofía y letras, Universidad de Buenos Aires. Tomo II.
BERMÚDEZ, O. 1984. Breve historia del salitre. Síntesis histórica desde sus orígenes hasta mediados del siglo XX. Ediciones Pampa Desnuda, Santiago.

BLAKEMORE, H. 1996. Historia del Ferrocarril de Antofagasta a Bolivia 1888-1988. Impresos Universitarios S.A., Santiago.

BREIGER, R. 1999. Control social y redes sociales: un modelo a partir de Georg Simmel. Politica y Sociedad 33: 57-72.

BOURDIEU, P. 1991. El sentido práctico. Editorial Taurus. Madrid. 1991a. La distinción. Criterio y bases sociales del gusto. Editorial Taurus. Madrid.

CABEZAS, A., M. I. Hernández, L. Núñez y M. Vázquez (Eds.), 2006. Las rutas del Capricornio Andino. Huellas milenarias de Antofagasta, San Pedro de Atacama, Jujuy y Salta. Consejo de Monumentos Nacionales, Santiago.

CARIOLA, C. y O. SUNKEL, 1982. La historia económica de Chile, 1830-1930. Instituto de Cooperación Iberoamericana, Madrid.

CENSO DE POBLACIÓN, 1908. República de Chile, levantado el 28 de noviembre de 1907. Imprenta Universo, Santiago.

CENSO DE POBLACIÓN, 1920. República de Chile, levantado el 15 de diciembre de 1920. Imprenta Universo, Santiago.

CENSO DE POBLACIÓN, 1931. Resultado del X Censo de la Población efectuado el 27 de noviembre de 1930 y estadísticas comparativas con censos anteriores. Imprenta Universo, Santiago.

CONTI, V. 2001. Salta entre el Atlántico y el Pacífico. Vinculaciones mercantiles y producciones durante el siglo XIX. EnCruzando la Cordillera... La frontera argentino-chilena como espacio social. S. Bandieri (Coord.), pp. 233-261. Universidad Nacional del Comahue, Argentina.

2003.El norte argentino y Atacama. Flujos mercantiles, producción y mercados en el siglo XIX. En Puna de Atacama, A. Benedetti (Comp.), pp. 21-52. Alción Editora, Córdoba.

CORCUFF, PH. 2005. Lo colectivo en el desafío de lo singular: partiendo del "habitus". En El trabajo sociológico de Pierre Bourdieu. Deudas y criticas, B. Lahire (Dir.), pp. 113-142. Siglo XXI Editores, Buenos Aires.

DELGADO, F. y B. GÖBEL, 2003.Departamento de Susques: la historia olvidada de la Puna de Atacama. En Puna de Atacama, A. Benedetti (Comp.), pp. 81-104. Alción Editora, Córdoba. 
DE FEDERICO DE LA RÚA, A. 2004. Los espacios sociales de la trasnacionalidad. Una tipología de la integración relacional de los migrantes. Redes. Revista hispana para el análisis de redes sociales 7: 125-150.

JUSTINIANO, M. F. 2003. La oferta ambiental y la construcción del Estado provincial salteño (1880 y 1914). Revista Escuela de Historia, vol. 1 (2). En línea, www.unsa.edu.ar/histocat/revista.

HARDOY, J. 1972. Las ciudades en América Latina. Seis ensayos sobre la urbanización contemporánea. Paidós, Buenos Aires.

GARCÉS, F. E. 1999. Las ciudades del salitre. Un estudio de las oficinas salitreras en la región de Antofagasta. Editorial Orígenes, Santiago.

GARCÍA, S. y D. ROLANDI, 2003. Antofagasta de la Sierra, provincia de Catamarca. Su historia en los documentos y la tradición oral. En Puna de Atacama, A. Benedetti (Comp.), pp. 137-198. Alción Editora, Córdoba.

GONZÁLEZ, S. 2002. Hombres y mujeres de la Pampa. Tarapacá en el ciclo de expansión del salitre. LOM/UNAP, Centro de Investigaciones Diego Barros Arana, Santiago.

GONZALEZ, J.A. 1993. Antofagasta en la época del salitre. Iglesia y sociedad en los procesos de urbanización y urbanismo. Notas Históricas y Geográficas 4: 41-72.

2001. Esquema de periodización de las relaciones entre el noroeste argentino y el norte chileno. En Cruzando la Cordillera... La frontera argentino-chilena como espacio social, S. Bandieri (Coord.), pp. 263-278. Universidad Nacional del Comahue.

2002. Espacio y política en Antofagasta en el ciclo salitrero. La percepción del desierto y el sentimiento regionalista, 18801930. En Una Tierra y Tres Nacionales. El litoral salitrero entre 1830 y 1930, V. Conti y M. Lagos (Comp.), pp. 251-292. Universidad Nacional de Jujuy, Jujuy.

2003. La pampa salitrera en Antofagasta. Auge y ocaso de una era histórica. La vida cotidiana durante los ciclos Shanks y Guggenheim en el desierto de Atacama. Corporación Pro Antofagasta, Antofagasta.

2008a. La conquista de una frontera. Mentalidades y tecnologías en las vías de comunicación en el desierto de Atacama. Revista de Geografia Norte Grande 40: 23-46.

2008b. La emigración boliviana en la precordillera de la región de Antofagasta: 1910-1930. Redes sociales y estudio de casos. Revista de Ciencias Sociales 21: 61-85.

2010a. La provincia de Antofagasta. Creación y consolidación de un territorio nuevo en el Estado chileno: 1888-1933. Revista de Indias vol. LXX (250): 345-380. 2010b. La industria minera de Antofagasta y la inmigración boliviana durante el ciclo salitrero. Notas para su estudio. Si Somos Americanos. Revista de Estudios Transfronterizos 10(2): 97-127.

2012. Privatization Versus Public Funding on the Atacama Desert Railway. An Interpretation. En Infraestructure, Design, Signalling and Security in Railway, X. Perpiña (Ed.), pp. 51-68. Ed. Intech, Croatia.

GUTIÉRREZ, R. 1983, Arquitectura y urbanismo en Iberoamérica. Cátedra, Madrid.

LEZAMA, J. L. 2005. Teoría social, espacio y ciudad. El Colegio de México, México.

MANUAL BAEDEKER DEL VIAJERO DE LA REPÚBLICA DE CHILE, 1910. Publicado por la Sociedad Editora Internacional. Imprenta y Litografía América, Santiago.

MICHEL, A., L. PÉREZ y E. SAVÍC, 1998. Exportaciones desde Salta al Norte Chileno. Fines del Siglo XIX y comienzos del XX. Revista de Estudios Trasandinos 2 (2): 99-114.

2000. Los vínculos argentinos chilenos a través de la Gobernación de Los Andes. Revista de Estudios Trasandinos 2: 63-75.

MORA, O. y P. ROMERO, 1999. Noa-Norte Grande. Crónica de dos regiones integradas. J.C. Productores Gráficos, Santiago.

MORSE, R. 1973. Lima en 1900. Instituto de Estudios Peruanos, Lima.

NADEL, S. F. 1966. Teoría de la estructura social. Editorial Guadarrama, Madrid.

PIEL, J. 1998., Region et nation en Amerique Latine: le cas du "Norte" Argentin (Tucumán, Salta, Jujuy) de 1778 á 1914. Bulletin de l'Institut Francais d'Etudes Andines 18(2): 299-350.

PIZARRO, N. 2004. Un nuevo enfoque sobre la equivalencia estructural: lugares y redes de lugares como herramientas para la teoría sociológica. Redes. Revista hispana para el análisis de redes sociales 5(2). En línea: http://redalyc.unamex.mx/src/inicio/ homrev.red.jsp

RAVENSTEIN, E.G. 1885.The Laws of Migration. Journal of the Royal Statistical Society 48: 167-227.

1889. The Laws of Migration. Journal of the Royal Statistical Society 52: 241-301.

SANHUEZA, C. 2001. Las poblaciones de la Puna de Atacama y su relación con los Estados Nacionales. Una lectura desde el Archivo. Revista de Historia Indígena 5: 55-82. 
SANHUEZA, C. y H. GUNDERMANN, 2007. Estado, expansión capitalista y sujetos sociales en Atacama (1879-1928). Estudios Atacameños 34: 113-136.

SCOBIE J. 1984. The growth of Latin America Cities, 1870-1930. En The Cambridge History of Latin America, L. Bethall (Ed.). Tomo IV, Cambridge.

SCHUTZ, A. 1974. El forastero. Ensayo de psicología social. En Estudios sobre teoría social. Amorrortu Editores, Buenos Aires.
SOLIMANO A. 2008. Migraciones internacionales en América Latina. Booms, Crisisy Desarrollo. Fondo de Cultura Económica, Santiago.

TALA, A. y J. A. GONZÁLEZ, 1996. Admisibilidad jurídica de un estatuto diferencial para el régimen de las aguas continentales en la Segunda Región de Chile. Revista de Derecho 3: 101-175.

VERGARA, A. 2008. Copper Workers, International Business, and Domestic Politics in Cold War Chile. The Pennsylvania State University Press. 